\title{
Root reinforcement dynamics in subalpine spruce forests following timber harvest: a case study in Canton Schwyz, Switzerland
}

Chiara Vergani ${ }^{\mathrm{a}}$, Massimiliano Schwarz ${ }^{\mathrm{a}}$, Mattia Soldati ${ }^{\mathrm{a}}$, Andrea Corda ${ }^{\mathrm{b}^{*}}$, Filippo Giadrossich ${ }^{\mathrm{b}}$, Enrico A. Chiaradia ${ }^{\mathrm{c}}$, Paola Morando ${ }^{\mathrm{c}}$, Chiara Bassanelli ${ }^{\mathrm{c}}$

${ }^{a}$ Bern University of Applied Sciences, Langgasse 85, 3052 Zollikofen, Switzerland

${ }^{b}$ Department of Agriculture, University of Sassari, via Enrico de Nicola 1, 07100 Sassari, Italy

${ }^{\mathrm{c}}$ Department of Agricultural and Environmental Sciences, University of Milan, via Celoria 2, Milano, Italy

* student

Correspondence to: C. Vergani, chiara.vergani@hotmail.com

\begin{abstract}
Root reinforcement is a key factor when dealing with slope stability problems and is an important quantitative criterion for the evaluation of the protective function of forests against shallow landslides, as well as for the adoption of appropriate practices in protection forest management. Although many models have been developed to estimate root reinforcement, a reliable quantification that considers both its spatial and temporal variability still remains a challenge. This work aims to extend the understanding of the long term spatial and temporal dynamics of root reinforcement after forest harvest in subalpine spruce forests by supplying new experimental data and applying a state-of-the-art model.

We estimated root reinforcement decay 5, 10 and 15 years after timber had been harvested in spruce stands in a small catchment in the Swiss Alps. We collected root distribution data at different distances from the trees and calibrated and validated a root distribution model (RootDis). To
\end{abstract}


estimate root mechanical properties, we tested roots up to $12 \mathrm{~mm}$ diameter in the field, and computed root reinforcement for each case study with the Root Bundle Model. Finally, we developed a new model for the estimation of root reinforcement decay, based on the observed change in root distribution after felling and on the decay of the root pullout force. The final result is a model for the spatial-temporal prediction of root reinforcement heterogeneity and dynamics in subalpine spruce forest stands. Five year old harvested spruce forest in the climatic conditions of the study area provides $40 \%$ of the root reinforcement of live forest, while 15 years old harvested forest provides no reinforcement at all. Shrub species and natural regeneration could guarantee almost the $30 \%$ of the root reinforcement of a live forest after 15 years from cutting. Additional work is now required to further validate the model and implement these results in a slope stability analysis.

Keywords: protection forests, shallow landslides, forest management, root reinforcement

\section{$1 \quad$ Introduction}

Trees significantly improve the stability of slopes through two different type of processes: the mechanical reinforcement of the soil provided by root systems and a complex range of hydrological effects like the rainfall interception by the canopy, the reduction of soil moisture through evapotranspiration and the modification of soil permeability and drainage due to the development of a macro pore system as a consequence of root growth. The mechanical effect of root systems has been recognized as one of the major contributions of vegetation to the mitigation of shallow landslides, especially in temperate climate regions (Sidle and Ochiai, 2006). Therefore, forests are considered as an important protection measure in the context of integrated risk management in the alpine area.

There are two different types of protection forests (Brang et al., 2006, Meloni et al., 2006): indirect and direct. Indirect protection forests provide a general level of protection, enhancing slope stability, reducing erosion and improving watershed conditions. This kind of forest in the steep 
areas also guarantees a mitigation of natural hazards, not primarily at a local scale, but at a regional scale (catchment area). Direct protection forests instead have as primary function the protection of settlements or infrastructure against the impacts of natural hazards. In the case of shallow landslides, forests may have both types of function; for this reason their management represents an extensive measure to ensure multiple fundamental ecosystem services.

The effectiveness and reliability of the protective function of a forest depends on the frequency, intensity, and dimensions of potential shallow landslides (Schwarz et al., 2010), and on the condition of the forest itself (Brang et al., 2006).

For this reason, the management of the protection forests is aimed to influence the forest dynamics in order to obtain an optimal protective effect and to improve the resilience of the system in case of disturbances.

The long-term capacity of protection forests is defined by the resistance to disturbances and by the recovery rate following disturbances. Therefore it is fundamental to understand and quantify root reinforcement dynamics after disturbances of both types: natural (such as bark beetle attacks, fires, wind-throw) and anthropogenic (timber harvesting and forestry practices in general). The reliable quantification of root reinforcement remains the main problem to solve in order to provide scientifically based support to forest managers.

Shallow landslides in forests are likely to occur within gaps of low root reinforcement or in areas where the root-thread strength has declined due to decay (Burroughs and Thomas, 1977). After tree death, the dense network of living root systems decreases both in density and strength, leaving unreinforced areas around the lateral edges of individual tree root systems (Schmidt et al., 2001). The observed increase in both number and density of shallow landslides after forest logging activities has motivated different studies on the effects of harvesting on root reinforcement (Burroughs and Thomas, 1977; Dhakal and Sidle, 2003; Preti, 2012; Sidle et al., 1991, 1992; Watson et al., 1999). Sakals and Sidle (2004) observed that the temporal dynamics of root reinforcement is usually assumed to be spatially uniform, which is, according to the authors, 
inappropriate because root distribution varies spatially and it has been proved that this variability can be huge as function of forest structure and patterns (Genet et al., 2010; Hales et al., 2009; Mao et al., 2012; Schmidt et al., 2001; Schwarz et al., 2010b, Vergani et al., 2014b). Nowadays, one of the main challenges is to consider both the spatial and temporal dynamics of root reinforcement, as this can be the key to understand landslide triggering mechanisms (Hales et al., 2013; Schmidt et al., 2001; Schwarz et al., 2012). With spatial dynamics of root reinforcement we mean the variability at the spatial scale, which depends mainly on the different distribution patterns of the root systems which are in turn depending on the forest type and the forest structure. The temporal dynamics instead is the variability along time, which depends on the natural evolution of the forest ecosystems (i.e. growth, senescence) and on the different disturbances occurring in the forest.

Most available studies on root reinforcement decay focus on root strength decay (Ammann et al., 2009; Johnson and Wilcock, 2002; Preti et al., 2012; Watson et al., 1999; Ziemer and Swanston, 1977) without considering the variation in root frequency and distribution, with a few exceptions (Burroughs and Thomas 1977, Schmidt et al., 2001; Vergani et al. 2014a). In these latter works there is an effort to consider the variation of roots number after felling, but the lack of information regarding the spatial variability of root distribution does not allow the upscale of results to the stand scale and then to the hillslope scale. Sakals and Sidle (2004) proposed a model for the spatial and temporal variability of root reinforcement, based on literature data and field data for a Pseudotsuga menziesii forest stand but they didn't consider the effect of the decay of the single elements that contribute to root reinforcement, i.e. strength and root density by class diameter. No studies consider the spatial and the temporal variability of root distribution after clear cut or disturbances for the alpine species in the literature so far.

This study aimed to extend the understanding of the long term temporal and spatial dynamics of root reinforcement in subalpine spruce forests, combining new experimental data with a modeling approach. Root reinforcement decay was estimated for a period of 15 years after timber harvesting using a state of the art modeling approach for the estimation of root reinforcement (Root Bundle 
Model, Schwarz et al., 2010b) and applying a new model for the estimation of root reinforcement decay based on the observed change in root distribution after felling and on the decay of root force over time. The final result of the study is a model for the spatial-temporal prediction of root reinforcement dynamics in managed spruce forest stands. .

\section{Material and Methods}

\subsection{Study area}

The study area is located in the small mountain catchment of Grosse Runs above the village of Obergross, in the Canton of Schwyz (Switzerland), with elevations ranging between $800 \mathrm{~m}$ and $1400 \mathrm{~m}$ a.s.l. The area is characterized by a high precipitation rate (on average $1800 \mathrm{~mm}$ per year, with peaks of $2300 \mathrm{~mm}$ per year). Average monthly temperatures range between $16^{\circ} \mathrm{C}$ in July and $2{ }^{\circ} \mathrm{C}$ in January. In 2007 there was a 300 years return period storm that caused a flood that transported a huge amount of wood (both live trees removed by the storm and drift wood) from the streams to the main river of the catchment and finally down to the village of Obergross. Clear cuttings were subsequently performed on the spruce forests on the stream banks to clean them up and avoid wood transport into the streams. Additionally, intense logging activities were performed on the slopes after the big storms of 1990 (Vivian) and of 1999 (Lothar), which destroyed large portions of forests.

Geologically, the basin is located in the flysch area of the northern alpine boundary (Ott et al., 1997) and is characterized by a substratum of sandstone (so called "flysch"), formed by different layers with non-permeable clay layers in between. This type of substratum formed soils with a strong clay component and which are easily eroded and produce big amounts of sediments. These geological patterns, combined with the climatic conditions and the steepness of the slopes cause erosions, shallow landslides (Fig. $1 \mathrm{a}$ and b) and floods. Active tension cracks are visible on logged slopes (Fig. 2). Field observation of shallow landslides reveals that the soil mantle is shallow, with maximum depths of $1-1.5 \mathrm{~m}$. 
Protection forests represent the $60 \%$ of the total forest cover in the canton Schwyz, and the main function in the considered basin is the protection against shallow landslides and floods. Predominant cover in the catchment is a mixed forest of Fagus sylvatica L. (beech), Abies alba Mill. (silver fir) and Picea abies L. H: Karst (Norway spruce), which is substituted by a forest dominated by Norway spruce at the higher elevations (from $1300 \mathrm{~m}$ a.s.1.). The dominance of spruce is partially due to a selection effect through human activities. The contemporary presence of large cut areas and slopes prone to shallow landslides makes the area representative for situations where forest management needs to take into consideration the protective function of forests.

Four sample sites were selected in the basin, at an altitude between $1300 \mathrm{~m}$ and $1400 \mathrm{~m}$ a.s.1., adopting a space-for-time substitution, which is a technique widely used in biodiversity modeling to infer past or future trajectories of ecological systems from contemporary spatial patterns. The slope angle in the selected sites ranged between 25 and $40^{\circ}$. Three sample sites (Tab. 1) were located in spruce forest cut areas where logging activity was conducted in 1998 (15 years old cutting), 2003 (10 years old cutting) and 2008 (5 years old cutting) respectively, while the fourth site (Tab. 1) was located in an undisturbed forest (control). The forest type, soil type and aspect was the same in every site to ensure comparable conditions. In each sample site the positions of 25 trees (or stumps) were determined through a high precision GPS device, and the species and the diameter at breast height $(\mathrm{DBH})$ of each tree were recorded. This information was then used to upscale the root distribution model from the sampled plants (or stumps) to the whole stand. The root distribution model adopted is explained in the section 2.4 of the materials and methods.

\subsection{Root distribution measurements}

We sampled root distribution following the method described in Schwarz et al. (2012). In each study site we selected five stumps (or trees in the control) with a diameter ranging between 30 and 40 centimeters. At each stump (or tree) we excavated three 50 x $50 \mathrm{~cm}$ wall trenches at 1.5, 2.5 and 4 meters from the stem in the down slope direction. We counted and measured roots with a caliper at each $5 \mathrm{~cm}$ depth layer, and classified them in $1 \mathrm{~mm}$ diameter classes, starting from $0.5 \mathrm{~mm}$. We 
excavated a total number of 15 trenches in the control forest and in the 10 year old cutting; in the 5 year old cutting we only excavated 14 trenches, because of the highly steep morphology of the slope. Finally, in the 15 year old cutting, 5 trenches, at a distance of 1.5 meters from the stumps, were considered enough to describe the area because spruce roots were widely degraded and shrubs uniformly distributed.

We counted the number of roots of the shrub species and natural regeneration (see table 1 for a complete list of the species) in the five trenches on the 15 year old site, where no spruce roots were present. As it was not possible to make a distinction between the roots of the different species, we classified them generally as "shrub and natural regeneration" roots. To classify the roots we adopted the root diameter classification proposed by Genet et al., 2008 and Ji et al., 2012, 0.5-1 mm (very fine roots), 1-2 $\mathrm{mm}$ (fine roots), 2-5 $\mathrm{mm}$ (thick roots), 5-10 $\mathrm{mm}$ (coarse roots), and over $10 \mathrm{~mm}$ (large roots).

\subsection{Root strength measurements}

We tested the mechanical properties of the root system using both pullout field tests and laboratory tensile tests (Bischetti et al., 2005). In the control forest and in the 5 years old cutting, 34 and 29 tensile tests were carried out, respectively, while it was not possible to pullout any roots in the 10 and 15 year old gap cutting due to their scarceness and their extremely degraded conditions. The diameters of the tested roots range between 2 and $13 \mathrm{~mm}$. Only roots oriented perpendicularly to the trench wall were selected for testing.

In the trench wall the soil was carefully removed to show at least 10 centimeters of each root (until 30 centimeters in the case of the bigger roots), then roots were cleaned and the bark removed. The reason for removing the bark was to avoid the slipping of the roots from the anchoring system. Each root was anchored to a metal ring using elastic wire and wood-metal glue. Each root was attached through its metal ring and a snap-hook to a load cell with a $200 \mathrm{~kg}$ capacity, which was linked through another snap hook to the crank handle. Then the crank handle was manually turned slowly and the root was constantly pulled out until it broke or slipped out. Always the same person was 
responsible for pulling roots to minimize errors associated with variations in test speed. A wired displacement sensor was fixed on a stake at a known distance from the trench wall. The extremity of the wire was fixed to the anchor of the root, in order to measure the displacement of the root subjected to the pullout procedure. The load cell and the displacement sensor were attached to a CR1000 data logger (Campbell Scientific), which recorded force (N) and displacement (mm) data each second. The diameter of each root was measured with a digital caliper at the breaking point, with bark, where possible (Schmidt et al., 2001). It was not possible to measure each root diameter with the bark, because sometimes the bark also broke and was removed at the breaking point. Therefore a linear regression between the measured diameter with and without bark was found both for the control forest (14 samples) and for the 5 year old gap (19 samples). In this way the diameter with bark of all the roots tested was estimated.

Finally, we performed laboratory tensile tests on roots from the control forest and the 5 year old cutting in order to compare the results coming from the field. In this case root diameters ranged between 1 and 6 millimeters instead of 1 to 13 (as in the field) due to clamping problems. Laboratory tensile tests were performed using an MTS testing machine equipped with a load cell (F.S. $500 \mathrm{~N}$, accuracy $0.1 \% \quad$ F.S.) and clamping devices that are able to avoid root damage at the clamping points. Only specimens that broke near the middle of the roots between clamps were considered valid. Root size with bark was estimated as the average of three values taken with a caliper at three points near the section of the potential breaking (Bischetti et al., 2009). The test speed was $10 \mathrm{~mm} / \mathrm{min}$ and the distance between the clamps was 5 centimeters.

To have an idea of natural regeneration and shrub species mechanical properties, we used the data obtained by tensile tests on roots of Vaccinium myrtillus L., Salix caprea L. and Rubus idaeus L. collected in 2012 in Italian Alps (Fig. A5), as representative of the richness in species communities. The procedure of testing was the same described for the spruce roots. 


\subsection{Root distribution model}

In order to upscale root reinforcement calculation at the hillslope scale, a root distribution model is needed. In the present study, root distribution was calculated using the model framework of Schwarz et al. (2012), RootDis, which considers the distribution of root diameters in a root system to be strongly correlated to the diameter of the tree stem, to the tree species and to the distance from the tree stem. In the following, the main features of the model are described. The number of roots of each diameter class $i$ at a given distance $d$ from the tree stem of diameter $\phi_{s}$ is:

$N_{i}(d)= \begin{cases}D_{f r}\left[\frac{\ln \left(1+\frac{\phi_{\max }}{\phi_{0}}\right)-\ln \left(1+\frac{\phi_{i}}{\phi_{0}}\right)}{\ln \left(1+\frac{\phi_{\max }}{\phi_{0}}\right)}\right]\left(\frac{\phi_{i}}{\phi_{0}}\right)^{\lambda} & \text { if } d<d_{\max } \\ 0 & \text { if } d>d_{\max }\end{cases}$

Where $d_{\max }$ is the maximum rooting distance from the tree stem, $D_{f r}$ is the density of fine roots

(number of fine roots per square meter), $\phi_{i}$ is the mean diameter of roots in class size $i, \phi_{0}$ is a

reference diameter equal to $1 \mathrm{~mm}, \phi_{\max }$ is the maximum root diameter that can be found at the

distance $d$, and $\lambda$ is an empirical exponent.

The distance $d_{\max }$ is given by:

$d_{\max }\left(\phi_{s}\right)=a_{0} \phi_{s}$

Where $a_{0}$ is proportionality constant. Both $D_{f r}$ and $\phi_{\max }$ depend on the distance from the tree stem:

$D_{f r}\left(d, \phi_{s}\right)=\frac{\mu \pi\left(\frac{\phi_{s}}{2}\right)^{2}}{d_{\max }}\left[\frac{0.7+\frac{0 . s d}{5 \phi_{s}}}{2 \pi\left(5 \phi_{s}\right)}\right] \quad$ if $\quad d<5 \phi_{s}$ 


$$
D_{f r}\left(d, \phi_{s}\right)=\frac{\mu \pi\left(\frac{\phi_{s}}{2}\right)^{2}}{d_{\max }} \frac{1}{2 \pi d} \quad \text { if } \quad d>5 \phi_{s}
$$

Where $\mu$ is a pipe-theory coefficient, and

$$
\begin{aligned}
& \phi_{\max }(d)=\frac{1}{r_{\text {ed_cosff }}} \frac{d_{\max }-d}{b} \phi_{0} \quad \text { if } \quad d<d_{\max } \\
& \phi_{\max }(d)=0 \quad \text { if } \quad d \geq d_{\max }
\end{aligned}
$$

Where red_coeff is the reduction coefficient accounting for the reduction of the root diameter after a branching point and $b$ is the average distance between root branches. Given the total number of fine roots belonging to a tree of a certain diameter, it is possible to estimate the number of fine roots per square meter. The model, based on the computing of the fine root biomass (roots of $1 \mathrm{~mm}$ in diameter) from which the number of the other roots is derived, applies to living trees only and was calibrated on root distributions sampled in the undisturbed forest (see Schwarz et al. (2012) for a more detailed description of the model itself).

The mean branching distance $b$ was kept constant at $90 \mathrm{~mm}$, as found by Schwarz et al., 2010 in experimental measurements on spruce roots. Then proportionality constant $a_{0}$ and the reduction coefficient red_coeff were calibrated in order to obtain values of maximum root diameter (eq. 5), using the data of the roots at $1.5 \mathrm{~m}$ distance, because we have the highest number of samples at this distance. The calibrated values of the proportionality constant (16.5) and reduction coefficient (0.9) were then kept constant. The pipe coefficient $\mu$ and the root distribution exponent $\lambda$ were calibrated based on the position and diameter of the trees and root distribution, searching the best fitting to minimize the sum of square errors (SSE).

From the 15 root distributions in the control forest, 7 were chosen for the calibration and 8 for the validation. Different combinations of trenches and trees were tested for the calibration (Tab. 2) 
before the validation was carried out on the remaining pits and plants. Finally, we choose the parameters combination that minimizes the error in both the calibration and validation (Tab. 2). The mean square error obtained in the undisturbed forest is 6 roots in the calibration and 9 roots in the validation. Considering that the mean total number of roots in a pit is 37 roots, the error (root of the mean squared error) is about the $6 \%$ in the calibration and $12 \%$ in the validation. Considering all the cases, the total mean error, evaluated as the sum of the differences between observed and simulated values, is 0.15 , showing a slight overestimation of the number of roots.

\subsection{Root reinforcement model}

Root reinforcement can be distinguished in basal reinforcement, given by the roots that intersect the shear plane of a landslide, and lateral reinforcement, given by the roots acting on the lateral edge of the landslide. Considering the shallow root system of Norway spruce, only lateral root reinforcement in this study was estimated, which has been proven to significantly affect the onset and size of shallow landslides (Reneau and Dietrich, 1987; Schmidt et al., 2001). Root reinforcement is calculated using the extended Root Bundle Model (RBMw) (Schwarz et al., 2013). The RBMw is a strain step loading fiber bundle model that implements the Weibull function in order to consider the variability of root mechanical properties. The RBMw assumes that neighboring roots do not influence the pullout force of a single root (Giadrossich et al., 2013). The inputs of the model are the tensile force, root length, and elasticity, as function of root diameter. The tensile force of a bundle of roots $F_{\text {tot }}$ is obtained as a function of displacement by summing the force contributions from each root $F$ multiplied by the survival function $S$ :

$F_{\text {tot }}(\Delta x)=\sum_{i=1}^{N} F\left(\phi_{i}, \Delta x\right) S\left(\Delta x_{i}^{*}\right)$

Where $\Delta x$ is the displacement, $\phi$ the root diameter and $i$ the diameter class. A detailed description of the model is presented in Schwarz et al. (2013). 
The force-diameter power laws used in the RBMw were obtained from root pullout tests (Tab. 3). Root length for each root diameter class has been estimated through the relationship proposed by Schwarz et al. (2013), where $\gamma=0.575$ and $\mathrm{L}_{0}=18.5(\mathrm{~m})$. Since the quality of field data on the displacement were not reliable due to the difficulty in the correct positioning of the displacement sensors, Young modulus (modulus of elasticity) was estimated for both degraded and healthy roots through the relationship proposed by Schwarz et al. (2013), where $\mathrm{E}_{0}=0.248^{*} 10^{8}(\mathrm{~Pa})$ and $\beta=-0.3$. Amman et al. 2009 proved that Young modulus do not depend on roots state of decay, and this result was confirmed by Marcandella, 2010. Root tortuosity was set equal to 1 since the equation for the estimation of the secant young modulus was calibrated with data obtained from field experiments that implicitly consider the effect of tortuosity. The steps followed for the calculation of force and displacement behavior of roots are presented in Schwarz et al. (2013). The calibrated Weibull distribution function parameters (exponent) are 2.58 for the control forest and 1.05 for the 5 years old harvested forest. The scaling factor is kept equal to one (Schwarz et al., 2013).

\subsection{Root population and strength decay model}

Root reinforcement decay after disturbances is due both to reduction in the number of roots and to reduction in their strength (Vergani et al., 2014a; Schmidt et al., 2001). Since the decay phenomena varies accordingly root diameter, in this work the two processes are analyzed separately.

In particular, as many natural phenomena are represented by an exponential growing/decay function (e.g. Odum and Barret, 2004) the number of roots for a certain diameter class $i(\mathrm{~mm})$ at the time $t$

(years) from the disturbance was estimated by an exponential decay function:

$$
N(i, t)=N_{0}(i) e^{-k(i) t}
$$

Where $N_{0}$ is the number of roots of the considered diameter class $i$ at the time $t=0$ (control forest) and $k$ is a decay parameter, which is expected to be a function of the diameter class $i$. 
To allow the calibration of the root number decay model, the parameter $k$ of each stand subject to disturbances ( 5 year cutting, 10 year cutting and 15 year cutting) was back calculated as follow:

$k(i)=-\frac{1}{t} \ln \left(\frac{N(i, t)}{N_{0}(i)}\right)$

Root distribution at the time zero, $N_{0}$, was estimated exactly in the position where the trenches were excavated with equation (1). The normalized values $N(i, t) / N_{0}(i)$ were then adopted to calibrate the model, where $N(i, t)$ is the number of roots at a certain time after cutting obtained by the sampling procedure. The calibration of the root population decay model was performed considering roots ranging between 1 and 8 millimeters, because roots over $8 \mathrm{~mm}$ in diameter were sporadic and their number was too small to model their degradation over time.

In few cases, the number of roots after cutting was higher than the number of roots at the time zero for the same distance from the stem. Therefore, in the cases where we obtained a ratio $N(i, t) / N_{0}(i)$ higher than one, we imposed a value equal to one because it was not realistic an increase in the number of roots with time after cutting.

The model adopted for the decay of the root force is an exponential function of time:

$F(t)=F_{0} e^{-c t}$

where $F_{0}=a \phi^{b}$ is the force power law of the roots at the time $t=0$ (with $\phi$ the root diameter) and $c$ is the decay coefficient. Coefficients $a$ and $b$ were calibrated from pullout test of live roots.

\section{Statistical analyses}

The dependence of root tensile force $(\mathrm{N})$ on root diameter $(\mathrm{mm})$ was described by a power law. The goodness of fit of the regression was estimated through the determination coefficient $\mathrm{R}^{2}$ and the significance coefficient ( $p$-value) obtained from Fisher's Test applied to the linear regression obtained from log-transformed values of force and diameter. To compare force values between live 
and degraded roots and take diameter into consideration as covariate (Hales et al., 2013; Vergani et al., 2012) ANalysis of COVAriance, ANCOVA, was applied to the linear regressions between the logarithmic transformation of diameter and pullout force, to assess if root decay affects root mechanical properties, with a level of confidence of $95 \%$. The normality and homogeneity of variance required for ANCOVA was verified using, respectively, Kolmogorov-Smirnov's test and Levene's test, both suitable for small samples, with a confidence level of 0.05 . The normality test was applied to log-transformed values and residuals; Levene's test was applied to log-transformed values. All statistical analyses were performed using R (R Core Team, 2014).

\section{Results}

\subsection{Root distribution}

At each distance from the stem the mean number of roots of each diameter class has been calculated, as the average of the number of roots counted in the 5 trenches excavated in each study

site (Fig. 3). The maximum measured root diameters at each stem distance are $57 \mathrm{~mm}$ at $1.5 \mathrm{~m}$ from the stem, $18 \mathrm{~mm}$ at $2.5 \mathrm{~m}, 78 \mathrm{~mm}$ at a distance of $4 \mathrm{~m}$. Assuming that about $80-90 \%$ of roots can be found in the first 50 centimeters of soil (Burke et al., 2002; Stokes et al., 2009) and considering the superficial, plate-like distribution of Norway spruce roots, the mean number of roots is scaled to 1 $\mathrm{m}$ width of soil multiplying by 2 the values of the measured data. When analyzing the mean root distribution with depth for each treatment (Fig. 4), we considered larger diameter classes (0-1 mm; 1-2 mm; 2-5 mm; 5-10 mm; > $10 \mathrm{~mm}$ ) in order to get a better view of the data. There is a consistent decrease in the number of roots as function of age of cutting areas. Moreover, only roots of diameter class equal to or bigger than 2-5 mm remained after 10 years from cutting, as consequence of degradation of the finest roots. Comparing undisturbed forests and gap cutting there was a reduction of $50 \%$ in the total number of roots in the first 5 years for any distance from the stem, with a significant decrease in the number of roots with diameter smaller than $5 \mathrm{~mm}$, but no significant decrease in roots with diameter greater than $5 \mathrm{~mm}$. 
After 10 years from cutting only roots with a diameter greater than $2 \mathrm{~mm}$ were found, and the decrease was evident and significant for all the remaining diameter classes. In this case the total number of roots fell to about $10 \%$ compared to the undisturbed forest values at 1.5 and 4 meters, and $24 \%$ at 2.5 meters.

No spruce roots were found in the 15 year old gap, with the exception of two large and severely degraded roots of 56 and $37 \mathrm{~mm}$. Shrub roots and others regeneration species roots were found (see Tab. A1 in the Appendix), and all roots had diameters smaller than $5 \mathrm{~mm}$ with the $83 \%$ of the roots with diameters smaller than $2 \mathrm{~mm}$.

\subsection{Root mechanical properties}

The relationship between the root pullout force at failure and the diameter can be approximated by a power law (Fig. 5a and Tab. 3). We found that maximum pullout force values range between $63 \mathrm{~N}$ and $2540 \mathrm{~N}$ for live roots, and between $25 \mathrm{~N}$ and $1530 \mathrm{~N}$ for 5 years old degraded roots. The loglinear regressions resulted different at the 0.05 level of significance (ANCOVA, $\mathrm{F}_{1,60}=7, \mathrm{p}=0.01$; corrected means: $289 \mathrm{~N}$ rotted roots and $475 \mathrm{~N}$ live roots).

In the laboratory tensile test (Fig. $5 \mathrm{~b}$ ), the maximum root force values found range between $11 \mathrm{~N}$ and $380 \mathrm{~N}$ for the undisturbed forest and between $10 \mathrm{~N}$ and $422 \mathrm{~N}$ for the 5 year old gap cutting. The log-linear regressions resulted different at the 0.05 level of significance (ANCOVA, $\mathrm{F}_{1,50}=5.7$, $\mathrm{p}=0.02$; corrected means: $74 \mathrm{~N}$ rotted roots and $103 \mathrm{~N}$ live roots ).

In order to compare tensile tests and pullout tests we considered only roots under $6 \mathrm{~mm}$ in diameter (the maximum diameter that could be tested in laboratory). Live roots log-linear regressions were different at the 0.05 level of significance (ANCOVA, $\mathrm{F}_{1,42}=6, \mathrm{p}=0.02$ ) while degraded roots were not different (ANCOVA, $\left.\mathrm{F}_{1,39}=1.19, \mathrm{p}=0.28\right)$.

\subsection{Root reinforcement estimation}

Root reinforcement is calculated in term of force-displacement curves (Fig. 6) for the control forest and the 5 year old gap cutting, considering the mean root distribution for each site and distance. In 
the undisturbed forest the peak force mobilized by the bundle of roots ranged between 1685 and $3725 \mathrm{~N}$ per square meter; in the 5 year old gap cutting they ranged between 552 and $1797 \mathrm{~N}$. Root reinforcement in the five years cut plot was lower than the one provided by live roots in a percentage ranging between 40 and $70 \%$ depending on the distance considered. Differences were higher (almost 70\%) at 2.5 meters from the stem, where the number of roots was in general lower. Displacement does not differ significantly due to the application of the same Young modulus both to live and degraded roots.

Concerning the 10 years old gap, no data on root mechanical properties were available, so they were obtained from the application of the force decay model (eq. 10) and used in combination with root distributions in the 10 year old gap. Considering the 15 years old gap, no old spruce roots were found in the five trench walls, therefore no reinforcement contribution from spruce was assumed. Fig. 7 a) shows the root reinforcement (in terms of maximum force values) decay after cutting. Force median values are $2708 \mathrm{~N}$ in the undisturbed forest, $1167 \mathrm{~N} 5$ years after cutting, $155 \mathrm{~N} 10$ years after cutting and $0 \mathrm{~N} 15$ years after cutting. The five years after cutting peak force median values are $43 \%$ of the control forest and the ten years after cutting peak force median values are $5 \%$ of control forest. Variability in root force values in the different position of the stand is higher in the control forest and decreases with time after cutting.

We computed the contribution of natural regeneration in the 15 years old gap (Fig. 7b) adopting the root distribution sampled in field (Tab. A1) and the root force diameter curve for shrubs and natural regeneration (Fig.A5).

We performed further simulations to evaluate which component has the major role in root reinforcement reduction, if the root strength decay or the change in root diameter distribution due to the decay process. Graphics of these simulations are shown in the Appendix. The first simulation (Fig. A1) estimates root reinforcement for the undisturbed forest and the 5 year old gap cutting considering in both cases the mean root distribution of undisturbed forests and changing just the root force -diameter curve and the Weibull coefficient. The five years after cutting root force 
ranges between 873 and 2031 N. Differences between live roots and degraded roots reinforcement range between 45 and $48 \%$. Similar results are obtained while considering all root distributions of the undisturbed forest (Fig. A 2) with a difference between the median force values of undisturbed forest and 5 years after cutting of $43 \% .10$ years after cutting (force values in the simulation are estimated with eq. 21) the median peak force values are about the $30 \%$ of undisturbed forest.

In the second simulation (Fig. A3) we adopted in all cases the control forest power law, Weibull coefficient and site specific root distribution. Five years after cutting force values increased with respect to the previous simulation and range between 1027 and 3413 N. Differences between live and rotted roots are $40 \%$ at 2.5 meters of distance and almost 0 at 4 meters of distance, and rotted roots have higher values of reinforcement $(+22 \%)$ at 1.5 meters distance, due to the presence of coarser roots $(>10 \mathrm{~mm})$. When considering all root distributions (Fig. A4) and simulating also the 10 years old gap the reduction in median root reinforcement values was $20 \% 5$ years after cutting and $80 \% 10$ years after cutting.

\subsection{Root population and strength decay model}

The values of the decay coefficient $k$ obtained for each diameter class from the calibration of eq. (8)

are reported in Fig. 8.

Considering roots until $8 \mathrm{~mm}$ in diameter, the trend of the $k$ value in function of the diameter class can be approximated by a power function with a value of $\mathrm{R}^{2}$ equal to 0.63 :

$k(i)=0.33 i^{-0.44}$

where $i$ is the diameter class (in $\mathrm{mm}$ ). The estimate of the number of roots for the diameter class between 1 and 8 millimeters with the eq. (11) had a mean error of -0.03 , showing a slight underestimation of the number of roots at the time $t$. The mean standard error is 0.13 . Then, we extended the function obtained to get the value $k$ for the bigger diameter classes.

Therefore $k$ values range between 0.33 for the smaller roots until almost zero for the bigger roots. 
Root force decay equation (eq. 10) was calibrated on the basis of the force-diameter power law of live roots and the one of the 5 year old degraded roots. We obtained $c=0.11$.

\subsection{Upscale of root reinforcement implementing spatial and temporal variability}

The calibrated parameters of the root distribution model (tab.2) were used to upscale root distribution at the stand level in the undisturbed forest (Fig. 9 a,b,c,d) using the information on the position and dimensions of trees recorded in the field. The same calibrated model was then applied to the 5,10 and 15 years old cut stands to estimate the root distribution before the disturbances.

Using the calibrated root population, strength decay model and the root distribution model, spatial and temporal variability of root reinforcement could be simulated. Fig. 9 a) shows the maximum lateral pullout force of the root bundles that cross a square meter surface in the undisturbed forest stand. Fig. 9 b), c), d) show the spatial and temporal variability of root reinforcement after 5, 10 and 15 years from cutting considering both the root decay model and the root force decay model.

\section{Discussion}

\subsection{Root distribution}

Few experimental data (Burroughs and Thomas, 1977; Schmidt et al., 2001; Vergani et al., 2014a) are available in literature concerning the change in root distribution after tree felling. Schmidt et al. (2001) measured root density in terms of root area ratio in clear cuts for eleven years and found that total root density was similar to the natural forests; however, considering live roots only we found a significant decrease. Based on our data, we observed a dramatic reduction of spruce roots after 10 years from cutting (between 80 and $90 \%$ of decrease compared with undisturbed forest) and almost no spruce roots are present after 15 years from cutting. In both the 10 year and 15 year gap there was a well-established natural regeneration, mainly of pioneer species. In the five trenches in the 15 year old cutting the roots of pioneer and brushwood species were counted (without distinguishing between species) to have an idea of the contribution of the newly established vegetation to root 
reinforcement. The mean total number of roots of the regeneration species is equal to the mean number of live spruce roots in the undisturbed forest, in agreement with the observation of Schmidt et al. (2001). It's important to note that root diameter distribution radically changes: there are no roots higher than $5 \mathrm{~mm}$ and almost the $60 \%$ of the roots is comprised between 0.5 and $1 \mathrm{~mm}$. This was demonstrated to have an impact on the shape and magnitude of root reinforcement curves (Vergani et al., 2014b).

The values of root number for diameter classes are comparable with the one reported by Schwarz et al., 2010b. Burroughs and Thomas found between 80 and 110 roots (of diameter $0.10 \mathrm{~mm}$ ) per square meter of soil in Coast Douglas Firs undisturbed forest and between 70 and 100 roots in Rocky Mountain Douglas Fir undisturbed forest. Vergani et al. (2014a) found for a mixed forest of Norway spruce - Silver fir 350 roots of diameter between 0.5 and $10 \mathrm{~mm}$ in a square meter of soil. Root distribution reflects both biological mechanisms and environmental factors and besides varying between vegetation communities it is spatially variable over distances of only few meters (Schmidt et al., 2001); also the methods adopted in the sampling probably have an influence on the recorded data (Vergani et al., 2014b).

Concerning the rate of root population decay, based on extrapolation of their experimental data, Burroughs and Thomas found no roots about 16 years after felling in the case of Coast Douglas Fir and 22 years after felling in the case of Rocky Mountains Douglas Fir. Five years after felling roots are slightly more than $10 \%$ in undisturbed forest in the first case and the $33 \%$ in the second case; 10 years after felling are the $10 \%$ and $20 \%$ in undisturbed forest. Our values showed a less severe decay in the first 5 years, but similar results at 10 years and 15 years after felling.

It has however to be considered that the estimation of the root distribution before cutting through a model involves a certain degree of uncertainty, even if the samples site were carefully choose to ensure the same initial conditions. The method of the space for time substitution necessary implies some simplifications, but it allows performing long term studies that would not be possible otherwise. 
The root distribution model estimates the number of roots in the tree stand with an error ranging between 6 and 12\%. Schwarz et al. (2012) found a value of pipe coefficient of 0.09 and an exponent of -1 for a mixed tree species stand at Ruedlingen, $\mathrm{CH}$, and values of reduction coefficient of 2.8 for a spruce stand at Uetliberg, $\mathrm{CH}$. Our values of exponents are comparable, while the pipe coefficient value is more than one order of magnitude inferior. Maximum distance coefficient is comparable with the one proposed by Schwarz (2012b). Significantly different is the reduction coefficient, because we imposed a reduction coefficient inferior than 1 in the eq. (5).

\subsection{Root mechanical properties}

Maximum root tensile force values obtained by pullout tests in the undisturbed forests range from 63 and $2540 \mathrm{~N}$ for roots between 2 and $13 \mathrm{~mm}$. Up to now the unique other data available derived by field pullout tests on spruce roots are those of Schwarz (2010b). In this case the maximum diameter tested was $3.7 \mathrm{~mm}$. Also considering laboratory tensile test there are few data regarding roots higher than $10 \mathrm{~mm}$. Gallotta (1999) found for different Mediterranean species (Prunus mahaleb and Pyrus pyraster) values of force of about 980 N. Ziemer and Swanston (1977) found for $10 \mathrm{~mm}$ roots of Sitka spruce values of about $1000 \mathrm{~N}$, which is comparable with our data. Data on the pullout force for $10 \mathrm{~mm}$ root diameter and higher provide useful values to better understand the trend of regression curve and the role of the bigger roots on root reinforcement.

In the case of live roots (from undisturbed forest) pullout force of elements with diameter smaller than $6 \mathrm{~mm}$ was significantly higher than tensile force. No difference was found considering five years old degraded roots. Hales et al. (2009) found that moisture content significantly affects cellulose content and as a consequence root strength, with root on noses (areas of divergent topography, lower moisture content) being stronger than roots in hollows (areas of convergent topography, higher moisture content); laboratory tested roots were conserved in a $15 \%$ alcohol solution so their moisture content was surely higher than field tested roots; but this doesn't seem to be the reason for the difference between live roots because it is not confirmed in the case of rotten roots. Tosi (2007) found that tensile strength values were higher in laboratory tensile tests than in 
field pullout tests. He explained this phenomenon with three different hypotheses: unfixed trench wall boundary; applied pullout force not perpendicular to the trench wall; presence of stones that damaged roots. In our case the highest values obtained for live roots in the pull out tests can be due to the root-soil friction and to the interactions between interlocking roots that increased the measured strength at rupture; in the case of degraded roots this did not happen, because root interactions are weaker due to partial degradation.

The 5 year old degraded roots were significantly weaker than live roots, considering both pullout and tensile tests. Corrected means of force values are about $30 \%$ inferior in 5 year degraded roots if we consider tensile test and $40 \%$ inferior if we consider pullout tests. Our values of root force decay fall between the range of values found by similar studies on spruce (Amman et al., 2009; Marcandella, 2010, in German). Marcandella (2010) found a higher rate of root force decrease, with 5 years degraded roots having values of tensile strength about $60 \%$ inferior than 3 years degraded roots. Amman et al. (2009), found a decrease of about 40\% in tensile strength of roots after 8 years from cutting. The fitting of the power law curve significantly gets worse in the 5 year case, due to a higher dispersion of data: the variability of root force values inside the same diameter class increases, because there are roots at different stages of degradation. This was found also by Vergani et al. (2014a) for 3 year degraded silver fir roots and by Marcandella, (2010) for degraded spruce fir roots collected in the same basin. The Weibull coefficient is an index that takes into account this variability, and significantly decreases in the case of the pullout test on degraded roots. The use of this coefficient is therefore important when modeling the mechanical behavior of rotten roots to consider force variability inside the same diameter class.

Comparing force values obtained by tensile test with the results obtained by Vergani et al. (2014a) on silver fir roots, live roots of spruce are significantly stronger than live silver fir roots; 5 year degraded roots are significantly stronger than 3 and 2 years degraded silver fir roots. Live spruce roots force values obtained in this study are in the range of the values obtained by live spruce roots from different sites in the Italian Alps (Vergani et al., 2012). 
Concerning root young modulus, we adopted the same diameter-young modulus function in both live and degraded roots. While some authors found no differences in elasticity modulus between live and degraded roots (Amman et al., 2009; Marcandella 2010), others instead did find some differences (Preti et al., 2012). It is probable that the degradation process affects root elastic properties, as the cellulose component is the first subject to degradation. Unfortunately our pullout data do not allow making conclusions about that, since further investigations are needed with regard to this point. In any case, Young modulus values computed on tensile test data were not different between live and rotted roots.

\subsection{Root decay model}

The model of the decay of the number of roots is based on the parameter $k$ which is a function of

root diameter. On the basis of our data, we found that $k$ depends on the root diameter class following a decreasing power law. Different studies observed a slower rate of decay in the bigger roots, which may be due to different factors: the lower leaching of the water soluble components (Fahey et al., 1988), the longer time needed to the fungi penetration (Foster and Lang, 1982; Berg, 1984), the presence of a major percentage of structural components and resistant materials in the roots of high diameter (Fitter, 1985). Some authors suggested that the faster degradation of fine roots is due to a higher concentration of nutrients, to a lower ratio nitrogen/lignin (Berg, 1984; Camirè et al., 1991) and to lower lignin content (Silver and Miya, 2001).

The root mean square error obtained by the model is always lower than one in each root diameter class. The model has to be validated using other data regarding spruce and other tree species to assess his reliability and to provide a suitable generalization based on an interpretation of the parameters.

Concerning root force decay model, an exponential function has been chosen instead of the linear function proposed by Preti (2012). Our model has been calibrated just on the force values 5 years 
from cutting, but it fits better to the literature data on spruce (Ammann et al., 2009, Marcandella, 2010) than a linear function (fig. A 6). The linear function has been proved to be more suitable for short time periods (Preti, 2012) and this is confirmed also by our data five years after cutting, but long term data are better interpreted by an exponential one: the application of a linear law would lead to a significant underestimation of force at higher time of degradation. Moreover it would lead to value of force negative from 12.5 years, which has no physical meaning and it is contrast to the findings of Marcandella (2010) who observed a slowing down of the degradation process after 10 years from disturbances, finding not significant differences between degraded and severely degraded roots.

\subsection{Root reinforcement dynamics along space and time}

Using the previously discussed data to compute root reinforcement, we found that after 5 years from cutting there was a reduction of reinforcement ranging between 40 and $70 \%$ (median values). The decrease is more severe at the distance of 2.5 meters from the stem, which is also the point where the minimum root number was found. This means that the points which are weaker on the slopes, due to root distribution patterns, are also the ones subjected to a most severe and fast reinforcement reduction after felling. After 10 years from cutting we have a reduction in the reinforcement of about $90 \%$, while we have no reinforcement at all provided by spruce fir roots 15 years after cutting.

The results of the simulation in fig. A1-A4 suggest that 5 years after cutting the decay in root reinforcement can be mainly attributed to root force decay, while root distribution doesn't play a critical role. It was difficult to obtain data regarding root mechanical properties after 10 years of cutting but we estimated it through the root force decay model; in any case, on the basis of Marcandella's findings (2010) who did not find any difference between mechanical properties of degraded and severely degraded roots, and on the basis of our data on root distribution, we can say that after 10 years from cutting the reduction in the number of roots has a predominant role in root reinforcement decay. The reduction in the number of roots is therefore critical in estimating the root 
reinforcement after cutting: for example, Marcandella, (2010) found that after 20 years of cutting degraded roots can still have the $54 \%$ of the strength of live roots; after 15 years however we almost did not find any roots of Norway spruce, so root number decay has to be taken into consideration for a reliable estimation of root reinforcement. On the other hand a big amount of natural renovation and shrub species has been found, especially in 10 and 15 year gaps. The contribution of shrub and regeneration species 15 year after cutting is $27 \%$ of the contribution of the undisturbed forest.

\section{Conclusions}

Root reinforcement decay was estimated along 15 years after timber harvesting and particular attention was given to the horizontal root distribution in the forest stand as suggested by recent studies (Schwarz et al., 2012). Root distribution was sampled systematically at different distances from the trees in order to characterize its spatial variability and to permit a more reliable estimation of the decay of root reinforcement at the slope scale. Moreover, roots bigger than 5 millimeters in diameter were tested in the field, to compensate the current lack of data regarding field pullout of roots of these dimensions.

The temporal variation of root reinforcement was calculated combining the decay of root mechanical properties and the decay of root frequency. The results showed that root reinforcement of the spruce forest in the climatic condition of our study area decrease to $60 \%$ of the initial value after 5 years from cutting, and completely vanished after 15 years.

The role of shrub species and natural regeneration after 15 years from cutting was found to guarantee almost the $30 \%$ of the root reinforcement of a live forest. The reinforcement provided by natural regeneration is therefore worth further research considering in particular woody regeneration species like Picea abies L. H. Karst itself, pioneer and ecologically interesting species as Betula pendula Roth, Sorbus aucuparia L., Acer pseudoplatanus L. The role of natural regeneration is in fact a key factor for the management strategies in protection forests, in order to preserve the resilience of the protection function. 
Root reinforcement is not homogeneous along the stand, but there are weaker points: the use of a root distribution model is therefore mandatory to correctly understand root reinforcement spatial dynamics. Furthermore, the use of the distribution model coupled with a decay model for both the number and the force of roots allows upscaling root reinforcement temporal and spatial dynamics at the stand scale.

Further work is needed to further validate the model and evaluate the sensitivity of the different parameters, in order to implement it in slope stability analysis to consider the effects of forest disturbances on root reinforcement as a possible critical factor in landslide triggering.

\section{Acknowledgements}

We are grateful to Stephen Lienert for the valuable help in the study sites selection, to Manfred Muhr who built the pullout machine, to the Forest Service personnel who helped us in digging the trenches, to Gian Battista Bischetti for providing the tensile test machine, to Mark Günter who revised the English and to the European Erasmus Placement Program.

\section{Appendix}




\section{References}

Ammann, M., Boll, A., Rickli, C., Speck, T., Holdenrieder, O., 2009. Significance of tree root decomposition for shallow landslides. For Snow Landsc Res 82:79-94.

Ammer, C., Wagner, S., 2005. An approach for modeling the mean fine root biomass of Norway spruce stands. Trees, 19: 145-153.

Berg, B., Johansson, M.B., Meentemeyer, V., Kratz, W., 1998. Decomposition of tree root litter in a climatic transect of coniferous forests in northern Europe: a synthesis. Scand J For Res 13:402-212. Bischetti, G.B., Chiaradia, E.A., Epis, T., Morlotti, E., 2009. Root cohesion of forest species in the Italian Alps. Plant and Soil, 324:71-89, DOI 10.1007/s11104-009-9941-0.

Brang, P., Schonenberger, W., Frehner, M., Schwitter, R., Thormann, J.J., Wasser, B., 2006. Management of protection forests in European Alps: an overview. For. Snow Landsc. Res. 80, 1: $23-44$.

Brunner, M., Bakker, M.R., Bjork, R.G. et al., 2012. Fine root turnover rates of European forests revisited: an analysis of data from sequential coring and ingrowth cores. Plant and Soil, 362:357372, DOI 10.1007/s11104-012-1313-5.

Burke, M.K., Raynal, D.J., 1994. Fine root growth phenology, production, and turnover in a northern hardwood forest ecosystem. Plant and Soil, 162:135-146.

Burroughs, E.R., Thomas, B.R., 1997. Declining root strength in douglas fir after felling: a factor in slope stability. USDA Forest service, Research paper INT-190.

Camiré, C., Côté, B., Brulotte, S., 1991. Decomposition of roots of black alder and hybrid poplar in short-rotation plantings: nitrogen and lignin control. Plant and Soil, 138:123-132.

Cohen, D., Schwarz, M., Or, D., 2011. An analytical fiber bundle model for pullout mechanics of root bundles. J. Geophys. Res., vol. 116, F03010, DOI:10.1029/2010JF001886.

Dhakal, A.S., Sidle, R.C., 2003. Long-term modelling of landslides for different forest management 
practices. Earth Surf. Process Land. 28:853-868.

Fahey, T.J., Hughes, J.W., Pu, M., Arthur, M.A., 1988. Root decomposition and nutrient flux following whole-tree harvest of northern hardwood forest. For. Sci. 34:744-768.

Fitter, A.H., 1985. Functional significance of root morphology and root system architecture. In:

Fitter AH, Atkinson D, Read DJ, Usher MB (eds) Ecological interactions in soil. British Ecological Society special publication no. 4. Blackwell, Oxford, pp 87-106.

Foster, J.R., Lang, G.E., 1982. Decomposition of red spruce and balsam fir boles in the White Mountains of New Hampshire. Can J. For. Res. 12:617-626.

Frehner, M., Wasser, B., Schwitter, R., 2005. Continuità nel bosco di protezione e controllo dell'efficacia (NaiS). Istruzioni per le cure nei boschi con funzione protettiva, AmbienteEsecuzione. Ufficio federale delle foreste, dell'ambiente e del paesaggio, Berna, $564 \mathrm{p}$. Gallotta, A., 2000. Contributo della vegetazione alla stabilità dei suoli declivi in ambiente mediterraneo. Tesi di dottorato in Idronomia. Ist. di Sistemazioni idraulico-forestali, Bari. 95pp. Genet, M., Kokutse, N., Stokes, A., Fourcaud, T.,Cai, X., Ji, J., Mickovski, S.., 2008. Root reinforcement in plantations of Cryptomeria Japonica D. Don: Effect of tree age and stand structure on slope stability. Forest Ecology and Management 256, 1517-1526.

Genet, M., Stokes, A., Fourcaud, T., Norris, J.E., 2010. The influence of plant diversity on slope stability in a moist evergreen deciduous forest. Ecological Engineering 36, 265-275.

Giadrossich, F., Schwarz, M., Cohen, D., Preti, F., Or, D., 2013. Mechanical interactions between neighbouring roots during pullout tests. Plant and Soil 367:391-406.

Ji, J., Kokutse, N., Genet, M., Forcaud, T., Zhang, Z., 2012. Effect of spatial variation of tree root characteristics on slope stability. A case study on Black Locust (Robinia pseudacacia) and Arborvitae (Platycladus orientalis) stands on the Loess Plateau, China. Catena 92:139-154. Mao, Z., Jourdan, C., Bonis, M.L., Pailler, F., Rey, H., Saint-Andrè, L., Stokes, A., 2012. Modelling root demography in heterogeneous mountain forests and applications for slope stability analysis. Plant and Soil DOI 10.1007/s11104-012-1324-2. 
Marcandella, D., 2010. Zugfestigkeit von Wurzeln von abgestorbenen Baumen. Bachelorarbeit (in German), ZAHW Wadenswil. 63S.

Hales, T.C., Ford, R.C., Hwang, T., Vose, J.M., Band, L.E., 2009. Topographic and ecologic controls on root reinforcement. J. Geophys. Res. 114, DOI:10.1029/2008JF001168.

Hales, T.C., Cole-Hawthorne, C., Lovell, L., Evans, S.L., 2013. Assessing the accuracy of simple field based root strength measurements. Plant and Soil, 372:553-565, DOI 10.1007/s11104-013$1765-2$.

Johnson, A.C., Wilcock, P., 2002. Association between cedar decline and hillslope stability in mountainous regions of southeast Alaska. Geomorphology 46, 129-142.

Odum, E., Barrett, G.W., 2004. Fundamentals of Ecology. Thomson Brooks/Cole.

Ott, E., Frehner, M., Frey, H-U., Lüscher, P., 1997. Gebirgsnadelwälder. Ein praxisorientierter Leitfaden für eine standortgerechte Waldbehandlung. Haupt; Bern, Stuttgart, Wien.

Pollen, N., Simon, A., 2005. Estimating the mechanical effects of riparian vegetation on streambank stability using a fiber bundle model. Water Res. Res. 41: W07025.

Preti, F. 2012. Forest protection and protection forest: Tree root degradation over hydrological shallow landslides triggering. Ecol.Eng. DOI 10.1016/j.ecoleng.2012.11.009.

R Core Team, 2014. R: A language and environment for statistical computing. R Foundation for Statistical Computing, Vienna, Austria. URL http://www.R-project.org/.

Reubens, B., Poesen, J., Canjon, F., Geudens, G., Muys, B. , 2007. The role of fine and coarse roots in shallow slope stability an soil erosion control with a focus on root system architecture: a review. Springer- Verlag. Trees 21:385- 402.

Reneau, S.L., Dietrich, W.E., 1987. Size and location of colluvial landslides in steep forested landscape. In Erosion and sedimentation in the Pacific Rim, Proceedings of the Corvallis Symposium, August 1987. IAHS Publication,165, 39-48.

Sakals, M.E., Sidle, R.C., 2004. A spatial and temporal model of root cohesion in forest soil. Can. J. For. Res., 34, 950-958. 
Schmidt, K.M., Roering, J.J., Stock, J.D., Dietrich, W.E., Montgomery, D.R., Schaub, T., 2001. The variability of root cohesion as an influence on shallow landslide susceptibility in the Oregon Coast Range. Can. Geotec. J, 38,995-1024.

Schwarz, M., Preti, F., Giadrossich, F., Lehmann, P., Or, D., 2010a. Quantifying the role of vegetation in slope stability: the Vinchiana case study (Tuscany, Italy). Ecological Engineering, $36(3), 285-291$.

Schwarz, M., Lehmann, P., Or, D. , 2010b. Quantifying lateral root reinforcement in steep slopes from a bundle of roots to tree stands. Earth Surf. Process. Landforms, 35, 354-367.

Schwarz, M., Cohen, D., Or, D., 2012. Spatial characterization of root reinforcement at stand scale: theory and case study. Geomophology, 171-172, 190-200.

Schwarz, M., Giadrossich, F., Cohen, D., 2013. Modeling root reinforcement using a root-failure Weibull survival function, Hydrol. Earth Syst. Sci., 17, 4367-4377, doi:10.5194/hess-17-4367. Sidle, R.C., 1991. A conceptual model of changes in root cohesion in response to vegetation management. J. Environ. Qual. 20:43-52.

Sidle, R.C., 1992. A theoretical model of the effects of timber harvesting on slope stability. Water Resour Res 28:1897-1910.

Sidle, R.C., Ochiai, H., 2006. Landslides: processes, prediction, and land use. Water resources monograph,18.

Silver, W.L., Miya, R.K., 2001. Global patterns in root decomposition: comparisons of climate and litter quality effects. Oecologia 129:407-419.

Stokes, A., Atger, C., Bengough, A.G., Fourcaud, T., Sidle, R.C., 2009. Desiderable plant root traits for protecting natural and engineered slopes against landslides. Plant and Soil 324:1-30.

Tosi, M., 2007. Root tensile strength relationships and their slope stability implications of three shrub species in the Northern Apennines (Italy). Geomorphology 87:268-283.

Vergani, C., Chiaradia, E.A., Bischetti, G.B., 2012. Variability in the tensile resistance of roots in alpine forest tree species. Ecological engineering, 46,43-56. 
Vergani, C., Chiaradia, E.A., Bassanelli, C., Bischetti, G.B., 2014a. Root strength and density decay after felling in a Silver Fir-Norway Spruce stand in the Italian Alps. Plant and Soil, 377:63-81, DOI10.1007/s11104-013-1860-4.

Vergani, C., Schwarz, M., Cohen, D., Thormann, J.J., Bischetti, G.B., 2014b. Effect of root tensile force and diameter distribution variability on root reinforcement in the Swiss and Italian Alps. Canadian Journal of Forest Research 10.1139/cjfr-2014-0095.

Watson, A., Phillips, C., Marden, M., 1999. Roost strength, growth, and rates of decay: root reinforcement changes of two three species and their contribution to slope stability. Plant and Soil, 217,39-47.

Ziemer, R.R., Swanston, D.N., 1977. Root strength changes after logging in southeast Alaska. USDA Forest Service Research Note. 


\section{List of figure captions}

Fig. 1a,b. Erosion phenomena and shallow landslide are common in the study area (Grosse Runs catchment, Canton Schwyz, CH)

Fig. 2 Tension cracks in the 5 years old cutting area (Grosse Runs catchment, Canton Schwyz, CH)

Fig. 3 Mean number and standard deviation of roots per diameter class in each treatment and at each distance from the stem

Fig. 4 Mean root distribution considering a trench wall of soil of 1 square meter at the different distances per each considered treatment. In the control forest total number of roots are: 42 at 1.5 meters from the stem, 21 at 2.5 meters, 49 at 4 meters; in the five years old cutting 23 at 1.5 meters, 11 at 2.5 meters, 18 at 4 meters; in the 10 year old cutting 4 at 1.5 meters, 5 at 2.5 meters, 4 at 4 meters.

Fig. 5 Root pullout tests (a) and tensile tests (b) results for undisturbed and 5 years old degraded roots.

Fig. 6 Root Bundle Model output in undisturbed forest and 5 year old gap cutting, considering a mean root distribution for $1.5,2.5$, and 4 meters distance from the stem; fmax $=$ maximum force mobilized by the root bundle; $\mathrm{dmax}=$ displacement at which the maximum force is reached.

Fig. 7 a Root reinforcement after cutting; measured root distributions and mechanical properties are considered in each site ( $n=15$ at 0 and 10 years, $n=14$ at 5 years, $n=5$ at 15 years). b: root reinforcement after cutting considering the contribution of shrubs and natural regeneration after 15 years from cutting.

Fig. 8 Values of the decay parameter $\mathrm{k}$ in function of the $1 \mathrm{~mm}$ diameter classes. 
Fig. 9 Map of root reinforcement (maximum force mobilized by the bundle of roots in one vertical square meter of soil), in the undisturbed forest at the time 0 (a) and after 5 (b), 10 (c) and 15 (d) years from an hypothetical cutting.

\section{List of figure captions (Appendix)}

Fig. A1 Output RBMw for undisturbed forest and 5 years old gap cutting, considering in all cases the mean root distribution of the undisturbed forest and changing just root mechanical properties (i.e weibull coefficient and root force power law).

Fig. A2 Root reinforcement values calculated with RBMw at each time after cutting considering in any case all root distributions of the undisturbed forest and changing just root mechanical properties

Fig. A3 Output RBMw for undisturbed forest and 5 years old gap cutting, considering in all cases the root mechanical properties (i.e weibull coefficient and root force power law) of the undisturbed forest and changing just root distribution

Fig. A4 Root reinforcement values calculated with RBMw at each time after cutting considering in any root mechanical properties of undisturbed forest and considering for each case all the root distributions sampled.

Fig. A5 Adventitious species force diameter power laws and general fitted power law adopted in RBMw simulation. $\mathrm{ra}=$ Rubus aedus, $\mathrm{sc}=$ Salix caprea, $\mathrm{vm}=$ Vaccinium myrtillus

Fig. A6 Comparison between the root strength decay model (dark line) and the experimental data of Amman et al., 2009 and Marcandella, 2010

\section{List of tables captions}

Table 1. Study site characterization. 
Table 2. Calibration and validation parameters in the control forest. The combination of parameters eventually chosen for the undisturbed forest is indicated with *. bis the distance between two branching points in a roots, red_coeff is the reduction coefficient, $\mu$ the pipe coefficient, $\lambda$ is the exponent for the root diameter distribution, $a_{0}$ is the maximum distance coefficient; SSE cal and val is the sum of square errors in the calibration and validation set; SSE val in the validation set; MSE cal and val is the mean square error in the calibration and validation set.

Table 3. Coefficients and statistical parameters of the power regressions F-d.

\section{List of tables captions (Appendix)}

Table A1. Mean number of roots at each distance in each sample site. in the 15 years old gap cutting there were no spruce roots, the number of roots of shrub species and regeneration species are reported. 